\title{
Treatments and technologies in the rehabilitation of apraxia and action disorganisation syndrome: A review
}

\author{
Andrew Worthington \\ Headwise, Claremont House, Claremont Bank, Shrewsbury SY1 1RW, UK \\ Tel.: +44 121222 5342; Fax: +44 121222 5340; E-mail: aworthington@headwise.org.uk
}

\begin{abstract}
.
BACKGROUND: Apraxia and Action Disorganisation Syndrome are characterised by an inability to use tools and carry out ordered sequences of movements in the absence of motor or sensory impairment. To date treatment for these complex but debilitating conditions has received little attention.

OBJECTIVES: To provide an overview of apraxia and action disorganisation syndrome and its treatment, providing a state of the art summary for practitioners including likely future therapeutic directions.

METHOD: Review of apraxia literature and treatment studies collated from internet searches involving MEDLINE, PubMed, PyscINFO and Google Scholar as well as the author's own catalogue.

RESULTS: Evidence for current restitution and compensatory approaches is critically reviewed, with limited evidence to date in support of either method. Strategy training is the most promising intervention type with no support for sensory and exploratory interventions, practice effects only for direct task-specific training, and modest support for gestural training.

CONCLUSIONS: Larger controlled studies are needed but evidence is sufficient to indicate certain approaches over others. Advances in assistive technology have not translated into mainstream therapy but future interventions are likely to require a model-based approach which embraces current technologies in order to provide a more accessible, effective and cost-efficient approach to rehabilitation.
\end{abstract}

Keywords: Apraxia, action disorganisation syndrome, cognitive rehabilitation

\section{Introduction}

The ability to improvise and use physical tools is one of the earliest defining characteristics of our ancestors and is believed to have provided the impetus for the development of gesture and ultimately language (Bradshaw \& Nettleton, 1982). Tool use both stimulated brain evolution and led to colonisation of a wider range of habitats, promoting neural, cognitive and ecological advancement (Iriki \& Taoka, 2012). Yet the development of brain regions specialised for language, tool use and action has made these abilities particularly vulnerable to the effects of cerebral damage. The systematic clinical study of disorders associated with defective tool use dates from the late 19th Century (Goldenberg, 2013). Since then examination of patients with these conditions has contributed greatly to our understanding of the complex organisation of gesture and object use and the inter-relationships with perception, language and memory, but this has not been matched by advances in treatment. This paper reviews the fascinating disorders of limb apraxia and action disorganisation syndrome in terms of clinical presentation, neuroanatomical basis and current theoretical understanding, and considers historical attempts at 
treatment. Reasons for the limited success of interventions to date are discussed and new approaches are introduced, informed by advances in neuroimaging, technology and neuropsychological theory that indicate how rehabilitation in the future is likely to be more efficient and clinically effective.

\section{Apraxia}

The term Apraxia is believed to have been first recorded in print in 1871 by Steinthal in a treatise on disorders of language but was not defined (Goldenberg, 2013). Other terms were in use around this time referring to apparent loss of memory for actions (mind-blindness) or inability to execute or comprehend gestures (asymbolia or asemia) but it was Liepmann (1900) who realised disorders of action could not be reduced to impaired object recognition and limb movement and who described the syndrome we recognise today as a disorder of skilled voluntary movement not attributable to motor, sensory or perceptual dysfunction. It is more commonly observed after left hemisphere brain damage (Donkervoort et al., 2000), often in association with aphasia, and tends to involve limbs bilaterally, even after unilateral lesions (but see Riddoch, et al. (1989) and Pilgrim \& Humphreys (1991) for exceptions). Clinically apraxia interferes with motor rehabilitation and undermines gestural communication in aphasic patients. Research also shows that apraxia causes significant problems in carrying out daily living tasks (van Heugten et al., 2000; Hanna-Pladdy, Heilman $\&$ Foundas, 2003) and is a factor in predicting posthospital care (Bjorneby \& Reinvang 1985; Giaquinto et al., 1999) and return to work (Saeki \& Hachisuka, 2004).

Following Liepmann subtypes of apraxia are usually identified by different patterns of performance on imitation of gestures, pantomiming object use and actual use of tools and other objects (Poek, 1986; van Heugten et al., 1999; Almeida et al., 2002; Vanbellingen, 2011). Conventionally patients who fail to recognise the meaning of a gesture or how to use an object are considered to have an 'ideational' form of apraxia attributable to inadequate activation or loss of knowledge of object use or action sequences. This is most evident in difficulties manipulating or miming use of real objects, for example a hairbrush maybe used as if it were a toothbrush (known as a content error) whereas gestures may be well formed but unrecognisable as they lack meaning.
By contrast some patients retain a concept of what they are trying to do but cannot carry out the action, which is characteristic of an 'ideomotor' apraxia, considered due to deficiency in translating the idea into required motor programs. This is often evident in poor performance of empty handed gestures after Liepmann who believed that the absence of cues from real objects was a more direct test of the translation from mental image to motor execution. Asking patients to imitate gestures rather than execute them to command may also reduce the emphasis on language.

Although apraxia is typically tested with gestures and single objects the complexity of real life tasks may reveal problems with single object use that are not identifiable on clinical examination, for example like using cutlery at mealtimes (Foundas et al., 1995). Ochipa, Rothi and Heilman (1992) proposed the term 'conceptual apraxia' to describe content errors with object use as opposed to sequence errors often made with multi-step actions.

Whilst left hemisphere damage typically disrupts performance of single gestures and sequences of actions (De Renzi et al., 1983), multi-step sequences are also impaired by right hemisphere and subcortical lesions (Canavan et al., 1989; Hanna-Pladdy et al., 2001; Soliveri et al., 2005). Luria (1973) cautioned against any temptation to try to localise apraxia in specific brain regions but acknowledged that frontal lesions produced a different type of apraxia characterised by "inability of the patient to subordinate his movements to the intention expressed in speech, the disintegration of organized programmes, and the replacement of a rational, goal-directed action by the echopraxic repetition of the patient's movements or by inert stereotypes which have lost their rational goal-directed character" (p.37). Consistent with this formulation a number of studies (e.g. Mayer et al., 1990) have now shown many different types of errors observed in multi-step actions that suggest loss of goal focus such as omitting steps in a sequence, perplexity (hesitations relating to objects) and toying (purposeless touching or lifting objects). Many of these have been captured in the development of the Naturalistic Action test (Schwartz et al., 2002), the first attempt to devise a clinical assessment tool for complex action.

Frontal apraxia as Luria conceived it challenges the notion that frontally-mediated executive processes operate only in non-routine situations (Shallice \& Burgess, 1996) but receives support from evidence from neurological patients that even routine 
actions may recruit working memory and attentional resources, at least at the level of individual subgoals in complex tasks (Schwartz, 1995). This has led to revision of the role of executive control in carrying out routine actions (Cooper, 2002).

Thus frontal apraxia has been explained by loss of top-down control leading to competing intentions in the case of callosal apraxia (Buxbaum et al., 1995) and in the presence of disruption to stored information about gesture and action (case JK: Schwartz et al., 1995). This leads to deficits of naturalistic action that have been observed after head injury (Schwartz et al., 1998), stroke (Schwartz et al., 1999) and dementia (Feyereisen, Gendron \& Seron, 1999; Giovannetti et al., 2002).

Whilst there is debate as to whether frontal apraxia and ideational apraxia are two distinct disorders what is clear is that apraxia is a complex syndrome incorporating multiple inputs and outputs involving conceptual (ideational) and ideomotor aspects. Some researchers have envisaged a set of modular processes in action production with several studies supporting the notion of pre-semantic stage involved in the recognition of visual gestures (an 'action input lexicon'), a conceptual store of information concerning tool use and gesture meaning, and an 'action output lexicon' i.e. a store of abstract motor programmes for learned motor responses which can be accessed via a semantic or non-semantic route, the latter being directly from a putative object recognition system (Rothi, Ochipa and Heilman, 1997). Hence FB, an agnosic patient could manipulate objects whose function he did not recognise (Sirigu et al., 1991). The role of executive functions in such a system is less clear but it is likely that deficient control processes play a part in at least some naturalistic action disorders although Schwartz et al. (1995) reported that multiple object performance correlated with tests measuring parietal but not frontal functions.

\section{Action disorganisation syndrome}

The term Action Disorganisation Syndrome (ADS) refers to the inability to carry out multi-step actions and arises from a form of double-deficit. Current thinking supposes that parietal lesions compromise movement descriptions (ideomotor apraxia) or how action programs are selected (ideational apraxia) whereas frontal lesions allow automatic action selection to proceed unchecked. Either of these dysfunctions alone may lead to impairment on testing but not necessarily in everyday life. In daily life functional reorganisation and compensation is achieved by executive processes utilising redundant information from touch, gesture representations and script knowledge. Thus Schwartz and Buxbaum (1997) argued that there is normally sufficient redundancy in the organisation of action that ideomotor patients for example, who cannot execute gestures accurately, can carry out actions reasonably well with real objects that incorporate the same gestural movements. Yet this process depends on adequate executive and other limited capacity resources such as arousal, attention and effort (Buxbaum, Schwartz \& Montgomery, 1998). Humphreys and Forde (1998) suggested Action Disorganisation Syndrome was caused by damage to stored knowledge of routine action schemas in the context of deficient supervisory attention control that would otherwise compensate for action slips. Support for this comes from a computational simulation of naturalistic action errors by Cooper and Shallice (2000). Their model distinguished between networks of action schemas, networks of object representations and activations, and a resource network within which resources compete for activation by corresponding object or action schemas. This model has been successfully applied to understanding patient errors (Rumiati et al., 2001).

\section{Approaches to treatment}

Given the importance of apraxia to long term disability the evidence base for effective treatment is surprisingly limited, perhaps due to the fact that apraxia is not a single disorder and successful intervention requires an understanding of what is to be rehabilitated. Several single case studies and exploratory group studies have been conducted but very few randomised control trials. For example Dovern, Fink and Weiss et al. (2012) found only three RCTs in a literature search from 1965 to 2011. Similarly only three RCTs were identified in a UK Cochrane review (West et al., 2008), leading the authors to conclude that there is insufficient evidence to support or refute the effectiveness of any specific therapeutic interventions for apraxia and much more high quality research is needed. Perhaps this is why standard textbooks on cognitive rehabilitation rarely include this challenging condition (e.g. Sohlberg \& Mateer, 2001; Ponsford, 2004; Halligan \& Wade, 2005). 
Many intervention studies also lack a clear theoretical rationale. Although all start with an assessment of apraxia in order to identify relevant cases, these assessments often lack a theoretical basis and even less likely are they used to inform the intervention. In part this is because there is no standard diagnostic process, no universal taxonomy of apraxia subtypes or theoretical consensus. Yet as noted by Wilson and Patterson (1990) therapy cannot afford to wait for guidance from theory. With this in mind the current approaches can be loosely grouped as being either restorative (sometimes called restitutive) or compensatory (also known as substitutive). The therapy studies described below are summarised in table 1 at the end of the review.

\section{Restorative treatment approaches}

To this category belong interventions which aim to restore impaired processing back to normal function. This has been attempted by trying to improve sensory integration, perceptuo-motor performance and selective attention. The sensory approach arose from perspectives on developmental dyspraxia and was underpinned by the notion that apraxia is due to failure to attend to or integrate functionally appropriate sensory information. Use of sensory stimulation protocols was reported to be beneficial in improving motor function in a single case of apraxia following head injury (Butler, 1997) though results did not include ADL measures. As other methods of visual cueing and verbal mediation were also used this was in effect a multimodal intervention. In another single case study (Butler, 2000) there was no evidence of a specific sensory stimulation protocol having any impact on motor function in a case of ideomotor apraxia. Bolduc and Lawrence (2011) reported a case using early constraint induced physical therapy for a man with hemiplegia and apraxia within two weeks of his stroke, which seems to have been successful in allowing him to maximise his potential for recovery by practising activities of daily living (ADL) tasks several hours a day.

Alternatively therapy has focused on perceptuomotor performance. Code and Gaunt (1986) reported improvements in learning Makaton signs in an aphasic patient with severe apraxia using a hierarchical intervention that involved gradual reduction of cues. Cubelli et al. (1991) trained an aphasic patient with apraxia to improve their gestural communication with an intervention that focused attention on salient features of gestures, but this failed to improve the underlying apraxic deficit (see also Daumuller and Goldenberg (2010) who reported practise effects with gestures and a degree of improvement on non-trained gestures). A similar approach incorporating object use was adopted by Smania et al. (2000). Using gesture training 13 patients were trained in object use and gesture with a therapist in three phases of increasing difficulty first by handling objects, then by being shown pictures of objects in use, and lastly by seeing object pictures and being asked to pantomime their use. Therapy lasted 35 sessions each of around 50 minutes. Progress through phases was based on achieving 17/20 items correctly. Pre- and post-training showed improvement on real objects and gesture. A subsequent study with 33 patients showed that improvements in gesture equated to improved ADL questionnaire ratings (this was not measured directly) with gains evident when reviewed two months post-treatment (Smania et al., 2006).

A rather different approach involves directing attention to key attributes of an object or gesture that can be used either to work out its possible use or to improve access to stored knowledge of action. In the latter case there is some evidence that it is possible to assist patients in carrying out everyday activities if they retained or could be taught by instructions. Thus Goldenberg and Hagmann (1998) reported a 'direct training' approach in which a single occupational therapist trained 15 severely apraxic patients in specific activities representing grooming, dressing and eating (brushing teeth, putting on a T-shirt or pullover and spreading margarine on a slice of bread). Therapy combined errorless completion and training in details and was delivered daily for two to five weeks. Two cases showed no success whilst others showed reductions in fatal (non-recoverable) errors on trained tasks. Follow-up ranged from six to 30 months which makes it difficult to draw conclusions about longer term outcome, especially in a small group, but it was suggested that progress was maintained only if activities were practised at home. Significantly there was no generalisation of gains to untrained activities. The authors surmised that patients had not learned how to infer possible functions for objects for which they did not retain instructions for use in long term memory.

An alternative 'exploratory' approach, focusing on restoring the ability to infer function from structure, was developed by Goldenberg et al. (2001) and compared with direct training. Therapists cued patients' attention to functionally significant aspects of objects and encouraged them to feel and draw the objects, 


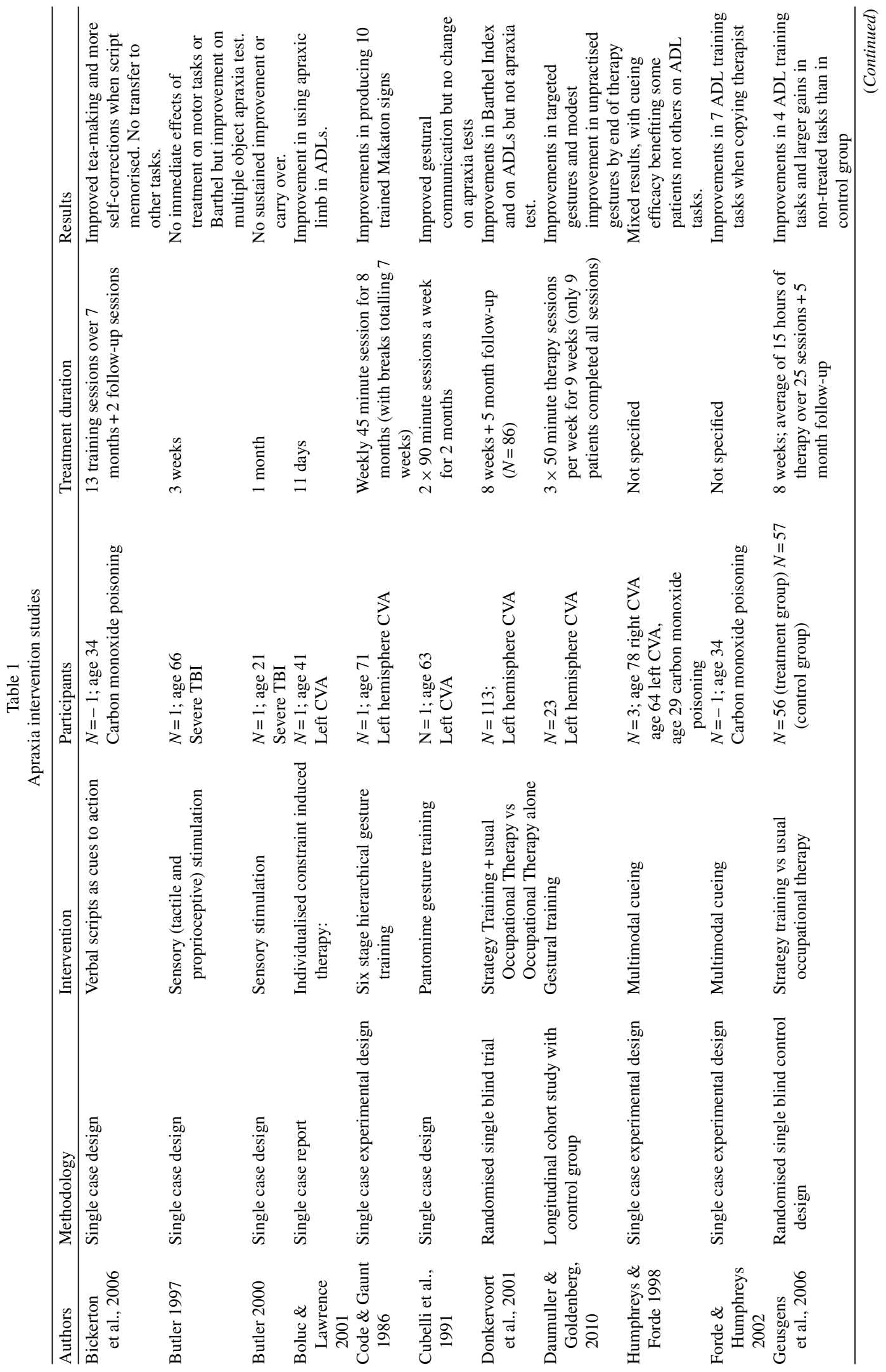




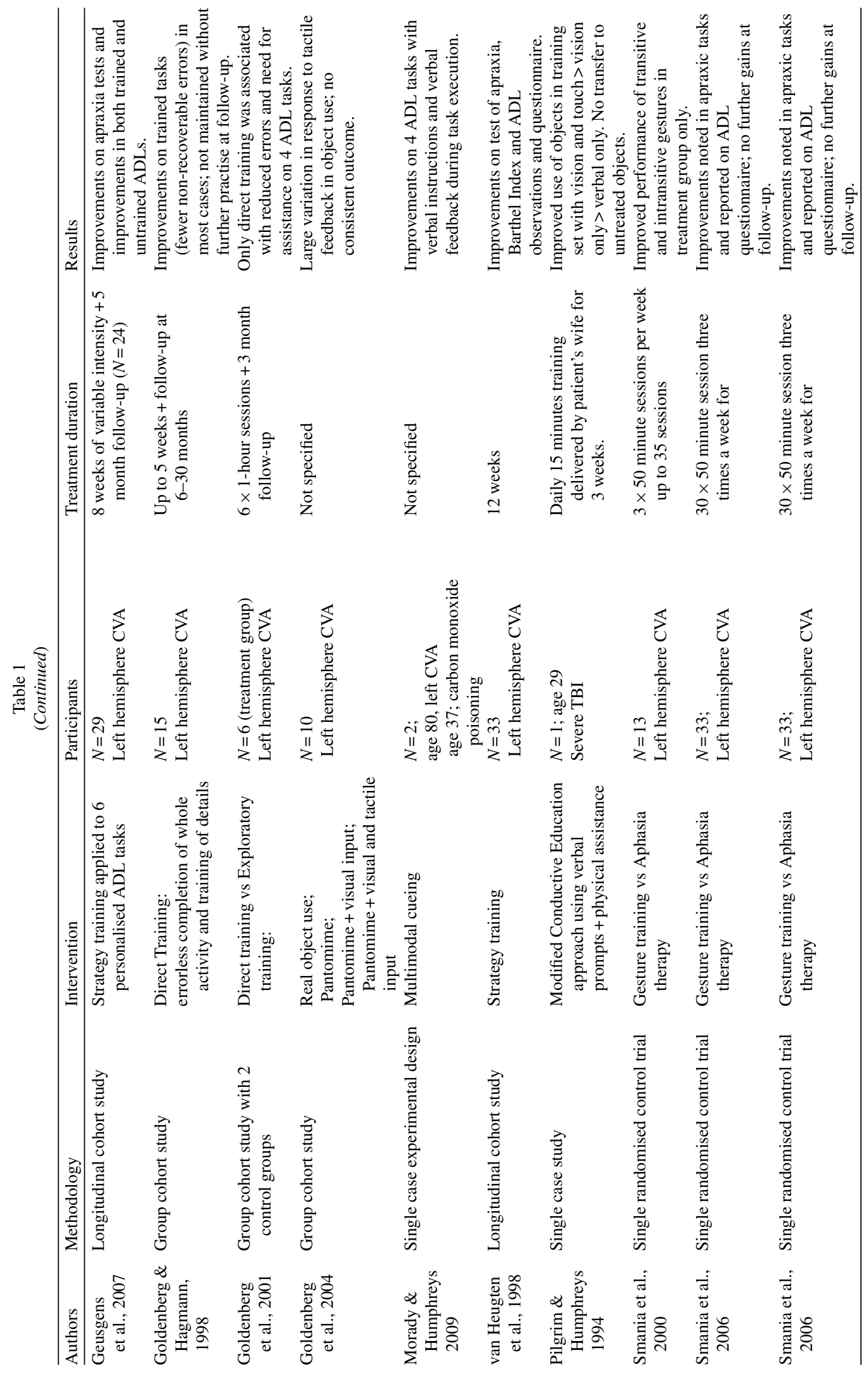


emphasising critical details. Six apraxic participants with aphasia were trained by two occupational therapists on four different ADL tasks (preparing coffee using an automatic coffee maker; changing batteries in a tape recorder, inserting a tape and playing it; cutting a slice of bread and spreading it with butter and jam; fixing a carpet knife and cutting out a cardboard rectangle). There was no benefit of exploratory training but benefits of direct training were replicated in that performance on training tasks improved but did not transfer to other activities. The authors concluded that therapy needs to be closely tailored to the patient's daily environment otherwise it remains an exercise in therapeutic efficiency with little relevance to the patient's normal life.

\section{Compensatory treatment approaches}

\subsection{Metacognitive interventions}

Compensatory methods focus on the disability associated with the apraxia and do not attempt to address the underlying impairment. One approach that has been described as a form of compensatory training by Cantagallo et al. (2012) is Strategy training, developed in The Netherlands. This can be distinguished from external compensatory methods as it relies on teaching internal strategies and is perhaps more informatively characterised as a form of metacognitive intervention.

Thus Strategy training method focuses not on training specific tasks, but on promoting generalisable skills (Stehmann-Saris, 2005). Van Heugten et al. (1998) reported improvements in ADLs (but not apraxia as measured on tests) with a 12-week occupational therapy training programme that focused on teaching strategies to overcome impairments. Treatment is based on a three-stage model of action (initiation /orientation; execution; control and correction) and provides a more individualised intervention. This was a clinical study rather than a carefully controlled research trial, involving 33 patients and 26 therapists in 16 hospitals. Patients were assessed on cognitive tests including apraxia tasks and their ADLs rated. Sessions of 30 minutes were delivered 3 to 5 times a week for 12 weeks and focused on various daily activities. Encouragingly, improvements were noted in ADLs independently of any change in apraxia, but patients were only 9 weeks post-stroke on average and outcomes were not blind-rated.
Donkervoort et al. (2001) subsequently reported a single blind controlled trial comparing standard occupational therapy with occupational therapy plus Strategy training. Patients were taught strategies to compensate internally (e.g. self-verbalisation) or externally (e.g. pictorial cues) in 15 hours on average over a mean of 25 sessions. Consistent with the aim to reduce disability rather than target impairment, improvements were noted for the treated group in ADLs but not in apraxia or motor functioning. It is possible that the benefits were short-lived as there were no differences between the strategy-trained and standard treatment group groups at 5 month followup but this may have also been because the latter were more likely to be still receiving therapy. In other words it may be that strategy training was the more effective intervention.

Further studies attempted to address the transfer of gains from treated to untreated tasks, intervention focusing on teaching ways to manage problems arising from apraxia rather than merely practising specific tasks (Geusgens et al., 2006). A large group of 113 left hemisphere stroke patients was randomly assigned to Strategy training or standard occupational therapy. After an eight-week treatment programme both interventions were associated with improvement on untrained as well as trained tasks but gains were larger in the Strategy training group.

Evidence of the effectiveness of this approach in generalising from hospital to home was reported by Geusgens et al. (2007). Strategy training was delivered over eight weeks in a rehabilitation centre and resulted in improvements on ADL tasks and on apraxia tests (with larger effect sizes for the former). Patients selected four ADL tasks and were trained on two, leaving the other two for comparison. As a group $(N=29)$ all tasks improved after treatment. Moreover there was no difference in trained and untrained tasks and performance at home versus the rehabilitation centre, indicating transfer to untrained tasks and generalisation to the home environment. Gains were maintained at follow-up at 20 weeks $(N=24)$.

\subsection{Assistive technology}

There are few naturalistic tasks nowadays that do not involve some form of technology, but this brings additional challenges. Evidence suggests that inferences about function drawn from structure are not particularly helpful when people are using 
technology (Hartmann, et al., 2005), which has implications for both technological design and the development of novel therapies. Nonetheless the scope to utilise technologies as compensatory aids for apraxia is greater than ever and there are many potential advantages. Current therapies in hospital are labour intensive and may not be delivered consistently all the time. Longer term gains rely on practice outside therapy sessions, which cannot easily be reinforced or monitored. Technological devices or systems however provide opportunity for consistent repetitive practice, can be adapted for home use, customised for individual patterns of disability, and can provide step by step prompting with a range of cues. An early example was Levinson's (1997) Planning and Execution Assistant and Trainer (PEAT) which addressed organisational aspects of behaviour. There a number of more recent micro-prompting systems such as the General User Interface for Disorders of Execution (GUIDE) system (O'Neill et al., 2010) but these are not designed for the complex disorders of praxis that characterise action disorganisation syndrome (see Jamieson \& Evans (2015) for a review).

In contrast to these passive devices are emerging more active systems which respond in real time or even anticipate errors. Key to this endeavour in the absence of a therapist is a means of obtaining information about how objects are being used, either by embedding sensors in objects or tracking their motion. A number of cognitive assistive technologies are now being developed using artificial intelligence that use sensory information about the world to make decisions on behalf of users and provide prompts accordingly.

The COACH system (Mihailidis et al., 2008) was designed to reduce care giver burden by prompting patients to complete everyday activities such as handwashing. It derives information about the world information via camera and provides audio and video cues. In between is a complex process of determining the intentions (belief states) of the user on a probabilistic basis in order to deliver cues effectively. Another system, which the author was involved in developing, is CogWatch (Hermsdorfer et al., 2013; Cogollor et al., 2014) that is specifically designed to provide errorless feedback and can be used as a training tool or compensatory aid. None of these systems has yet progressed to a point where they can be used in large scale trials but they do indicate the direction in which assistive technology is developing.

\section{Future therapies}

Future therapies are likely to benefit from theoretical and technological advancements. Most interventions to date have a tenuous link to theory but the development of more effective rehabilitation interventions will be informed by cognitive models of praxis by increasing understanding of potential mechanisms of action. For instance in the Cooper and Shallice (2000) model object representations are activated by the environment and from action schema, and can also act to trigger schema. This means that therapists can use a top-down goal prompt (for example a verbal cue to 'make coffee') or highlight relevant objects (e.g. a coffee pot) to trigger the appropriate schema (make coffee).

The top-down approach seeks to focus on highlighting task objectives whether by activating action knowledge or maintaining a goal in working memory. Verbal instructions from a therapist whilst carrying out actions may assist in selection of correct action sequences (addressing an ideomotor deficit) or in augmenting stored semantic knowledge, as suggested by the efficacy of a conductive education approach utilised by Pilgrim \& Humphreys (1994), although this was beset by the common finding of lack of generalisation to non-trained objects, suggesting that benefits may be limited to specific object representations. Greater emphasis in therapy design on principles of motor learning may help overcome this problem (Buxbaum et al., 2008).

Alternatively patients might be taught via mnemonics or other devices to retain instructions. Bickerton, Humphreys and Riddoch (2006) for example demonstrated that by memorising a set of cues in the form of a brief poem (within the patient's digit span) their case FK was able to make a cup of tea, although whether this was by using a phonological loop as compensation for other working memory deficiencies or by restoring long term verbal script knowledge was unclear. Whereas another ADS case, HG, benefitted from written cues (Humphreys \& Forde, 1998) FK's performance did not, but it did improve by copying task steps carried out by an instructor, possibly because residual stored action knowledge was more effectively engaged by the sensorimotor cues involved in copying or alternatively in bypassing the need to access action semantics altogether (Forde \& Humphreys, 2002). Such a strategy that could be particularly helpful in certain dementias where loss of object knowledge underlies ADL impairment (Hodges et al., 2000). 
The efficacy of sensory information such as environmental sounds and motion cues supports the view that there are several functionally isolatable processing routes (visual, auditory, tactile) contributing to normal action. These may operate as parallel independent pathways (the multiple route model) or act conjointly to determine access to stored representations (convergent model). The common observation that apraxic patients benefit using real objects (De Renzi \& Luchelli, 1988) suggests that perceptual information from the objects aids selection of appropriate action (Chainay \& Humphreys, 2002). Multimodal cueing is therefore another promising strategy yet to be exploited clinically, although Goldenberg et al. (2004) reported that tactile feedback is optimally effective when derived from objects during actual use.

The profile of patient errors is also likely to be important in identifying appropriate treatment methods, with more studies needed on matching interventions to clinical characteristics. This will entail a move away from thinking in terms of apraxic syndromes to a more functional characterisation of apraxic deficits linked to cognitive models of normal praxis. We know that even healthy participants are likely to make errors in naturalistic tasks when required to carry out concurrent tasks that occupy executive processes (Morady \& Humphreys, 2009) and apraxic patients' performance improves with interventions aimed to reduce reliance on internally generated action schema and having to monitor their errors (Morady \& Humphreys, 2011). Giovannetti et al. (2008) suggested that individuals with predominant omission errors may benefit from repetitive practice, checklists and other reminders whereas patients tending to make commission errors would benefit more from interventions that seek to reestablish cognitive control over performance such as Goal Management Training (Manly et al., 2002).

\section{Conclusions}

The complexity of apraxia and action disorganisation syndrome and the rather esoteric nature of much of the literature concerning this topic mean that for many therapists the subject remains distant and obtuse. Yet there is a small but growing evidence base for rehabilitation with Cappa et al. (2005) attributing grade A to evidence for the effectiveness of compensatory approaches for treating apraxia. Likewise Cicerone et al. (2005) recommended specific gestural or Strategy training as a new practice standard for apraxia as it was superior to sensorimotor or aphasia therapies. There have been no studies of the cost-effectiveness of apraxic rehabilitation but efforts to develop a more theoretically-informed approach to intervention should be embraced as this is most likely to lead to targeted and therefore more costefficient interventions in future. The potential of assistive technologies to improve what are currently labour intensive and largely task-specific treatments is considerable but as yet unrealised. Future collaboration between developers and clinicians should see the gradual emergence of a new paradigm for intervention in this area. As the evidence base is currently limited to a handful of RCTs and case studies the need for larger scale controlled research remains but group studies allow for analysis of individual profiles and response patterns so that personalised interventions can be informed by explicit models of apraxic disorders.

\section{Acknowledgments}

The author dedicates this paper to the memory of Professor Glyn Humphreys and gratefully acknowledges the contributions of all members of the CogWatch team for their varied insights and expertise in the area of apraxia and action disorganisation syndrome.

\section{Conflict of interest}

The work in this paper was supported in part by the EU STREP Project CogWatch (FP7-ICT-288912).

\section{References}

Almeida, Q. J., Black, S. E., \& Roy, E. A. (2002). Screening for apraxia: A short assessment for stroke patients. Brain and Cognition, 48, 253-631.

Bickerton, W. L., Humphreys, G. W., \& Riddoch, M. J. (2006). The use of memorised verbal scripts in the rehabilitation of action disorganisation syndrome. Neuropsychological Rehabilitation, 16, 155-177.

Bjorneby, E. R., \& Reinvang, I. R. (1985). Acquiring and maintaining self-care skills after stroke. Scandinavian Journal of Rehabilitation Medicine, 17, 75-80.

Bolduc, J. J., \& Lawrence S. (2011). Constraint induced movement therapy: Treating hemiplegia and apraxia following an acute stroke. OT Practice, 16, 12-16.

Bradshaw, J. L., \& Nettleton, N. C. (1982). Language lateralization to the dominant hemisphere: Tool use, gesture and language 
in hominid evolution. Clinical Psychological Reviews, 2, 171192.

Butler, J. A. (1997). Intervention effectiveness: Evidence from a case study of ideomotor and ideational apraxia. British Journal of Occupational Therapy, 60(11), 491-497.

Butler, J. A. (2000). Rehabilitation in severe ideomotor apraxia using sensory stimulation strategies: A single case experimental design study. British Journal of Occupational Therapy, 63(7), 319-328.

Buxbaum, L. J., Schwartz, M. F., Coslett, H. B., \& Carew, T. G. (1995). Naturalistic action and praxis in callosal apraxia. Neurocase, 1(1), 3-17.

Buxbaum, L. J., Schwartz, M. F., \& Montgomery, M. W. (1998). Ideational Apraxia and naturalistic action. Cognitive Neuropsychology, 15, 617-664.

Buxbaum, L. J., Haal, K. Y., Hallett, M., Wheaton, L., Heilman, K. M., Rodriguez, A., \& Gonzalez Rothi, L. J. (2008). Treatment of limb apraxia: Moving forward to improved action. American Journal of Physical Medicine and Rehabilitation, 87(2), 149161.

Canavan, A. G. M., Passingham, R. E., Marsden, C. D., Quinn, N., Wyke, M., \& Polkey, C. E. (1989). Sequencing ability in Parkinsonians, patients with frontal lobe lesions and patients who have undergone unilateral temporal lobectomies. $\mathrm{Neu}$ ropsychologia, 27, 787-798.

Cantagallo, A., Maini, M., \& Rumiati, R. I. (2012). The cognitive rehabilitation of limb apraxia in patients with stroke. Neuropsychological Rehabilitation, 22(3), 473-488.

Cappa, S. F., Benke, T., Clarke, S., Rossi, B., van Stemmer, B., \& Heugten, C. M. (2005). EFNS guidelines on cognitive rehabilitation: Report of an EFNS Task Force. European Journal of Neurology, 12, 665-680.

Chainay, H., \& Humphreys, G. W. (2002). Neuropsychological evidence for a convergent route model for action. Cognitive Neuropsychology, 19(1), 67-93.

Cicerone, K. D., Dahlberg, C., Malec, J. F., Langenbahn, D. M., Felicetti, T., Kneipp, S., Ellmo, W., Kalmar, K., Giacino, J. T., Harley, J. P., Laatsch, L., Morse, P. A., \& Cantanese, J. (2005). Evidence based cognitive rehabilitation: Updated review of the literature from 1998 through 2002. Archives of Physical Medicine and Rehabilitation, 86, 1681-1692.

Code, C., \& Gaunt, C. (1986). Treating severe speech and limb apraxia in a case of aphasia. British Journal of Disorders of Communication, 21, 11-20.

Cogollor, J. M., Pastorino, M., Rojo, J., Fioranvanti, F., Wing, A., Arrendondo, M. T., Ferre, M., Brenosa, J., Hermsdorfer, J., De Teresa, J., Walton, C., Worthington, A., \& Giachritsis, C. (2014). An innovative solution based on human computer interaction to support cognitive rehabilitation. Journal of Accessibility and Design for All, 4(3), 238-254

Cooper, R. (2002). Order and disorder in everyday action: The roles of contention scheduling and supervisory attention. Neurocase, $8,61-79$.

Cooper, R., \& Shallice, T. (2000). Contention Scheduling and the control of routine activities. Cognitive Neuropsychology, 17(4), 297-338.

Cubelli, R., Trentini, P., \& Montagna, C. G. (1991). Re-education of gestural communication in a case of chronic global aphasia and limb apraxia. Cognitive Neuropsychology, 8(5), 369-380.
Daumuller, M., \& Goldenberg, G. (2010). Therapy to improve gestural expression in aphasia: A controlled clinical trial. Clinical Rehabilitation, 24(1), 66-86.

De Renzi, E., \& Luchelli, F. (1988). Ideational apraxia. Brain, 111, 1173-1185.

De Renzi, E., Faglioni, P., Lodesani, M., \& Vecchi, A. (1983). Performance of left brain-damaged patients on imitation of single movements and motor sequences. Frontal and parietalinjured patients compared. Cortex, 19, 333-343.

Donkervoort, M., Dekker, J., van den Ende, E., Stehmann-Saris, J. C., \& Deelman, B. G. (2000). Prevalence of apraxia among patients with a first left hemisphere stroke in rehabilitation centres and nursing homes. Clinical Rehabilitation, 14, 130136.

Donkervoort, M., Dekker, J., Stehmann-Saris, F. C., \& Deeolman, B. G. (2001). Efficacy of strategy training in left hemisphere stroke patients with apraxia: A randomised clinical trial. $\mathrm{Neu}$ ropsychological Rehabilitation, 11(5), 549-566.

Dovern, A., Fink, G. R., \& Weiss, P. H. (2012). Diagnosis and treatment of upper limb apraxia. Journal of Neurology, 259 (7), 1269-1283.

Feyereisen, P., Gendron, M., \& Seron, X. (1999). Disorders of everyday actions in subjects suffering from senile dementia of Alzheimer's Type: An analysis of dressing performance. Neuropsychological Rehabilitation, 9(2), 169-188.

Forde, E., \& Humphreys, E. (2002). Dissociations in routine behaviour across patients and everyday tasks. Neurocase 8 , 151-167.

Foundas, A. L., Macauley, B. L., Raymer, A. M., Maher, L. M., Heilman, K. M., \& Rothi, L. J. G. (1995). Ecological implications of limb apraxia: Evidence from mealtime behavior. Journal of the International Neuropsychological Society, 1, 62-66.

Geusgens, C. A. V., van Heugten, C. M., Donkervoort, M., van den Ende, E., \& van den Heuvel, W. (2006). Transfer of training effects in stroke patients with apraxia: An exploratory study. Neuropsychological Rehabilitation, 16(2), 213-229.

Geusgens, C. A. V., van Heugten, C. M., Cooijmans, J. P. J., Jolles, J., \& van den Heuvel, W. J. A. (2007). Transfer effects of a cognitive strategy training for stroke patients with apraxia. Journal of Clinical and Experimental Neuropsychology, 29(8), 831-841.

Giaquinto, S., \& Buzzelli, S., Di Francesco, L., Lottarini, A., Monenero, P., Tonin, P., Nolfe, G. (1999). On the prognosis of outcome after stroke. Acta Neurologica Scandinavia, 100, 202-208.

Giovannetti, T., Libon, D. J. K., Buxbaum, L. J., \& Schwartz, M. F. (2002). Naturalistic action impairments in dementia. Neuropsychologia, 40, 1220-1232.

Giovanetti, T., Bettcher, B. M., Brennan, L., Libon, D. J., Kessler, R. K., \& Duey, K. (2008). Coffee with jelly or unbuttered toast: Commissions and omissions are dissociable aspects of everyday action impairment in Alzheimer's Disease. Neuropsychology, 22(2), 235-245.

Goldenberg, G. (2013). Apraxia. The cognitive side of motor control. New York: Oxford University Press, 273.

Goldenberg, G., \& Hagmann, S. (1998). Therapy of activities of daily living in patients with apraxia. Neuropsychological Rehabilitation, 8(2), 123-141.

Goldenberg, G., Daumuller, M., \& Hagmann, S. (2001). Assessment and therapy of complex activities of daily living in apraxia. Neuropsychological Rehabilitation, 11(2), 147-169. 
Goldenberg, G., Hentze, S., \& Hermsdorfer, J. (2004). The effect of tactile feedback on pantomime of tool use in apraxia. $\mathrm{Neu}$ rology, 63, 1863-1867.

Halligan, P. W., \& Wade, D. T. (2005). Effectiveness of Rehabilitation for Cognitive Deficits. New York: Oxford University Press, 397.

Hanna-Pladdy, B., Heilman, K., \& Foundas, A. L., (2001). Cortical and subcortical contributions to ideomotor apraxia. Brain, 124, 2513-2527.

Hanna-Pladdy, B., Heilman, K. M., \& Foundas, A. L. (2003). Ecological implications of ideomotor apraxia. Neurology, 60(3), 487-490.

Hartmann, K., Goldenberg, G., Daumuller, M., \& Hermsdorfer, J. (2005). It takes the whole brain to make a cup of coffee: The neuropsychology of naturalistic actions involving technical devices. Neuropsychologia, 43, 625-657.

Hermsdorfer, J., Bienkiewicz, M., Cogollor, J. M., Russel, M., Jean-Baptiste, E., Parekh, M., Wing, A. M., Ferre, M., \& Hughes C. (2013). CogWatch - Automated Assistant and rehabilitation of stroke-induced action disorders in the home environment. In: Harris D (Ed) Engineering Psychology and Cognitive Ergonomics. Applications and Services 8020, Berlin: Springer-Verlag, 343-350.

Heugten, C. M., van Dekker, J., Deelman, B. G., van Dijk, A. J., Stehmann-Saris, J. C., \& Kinebanian, A. (1998). Outcome of strategy training in stroke patients with apraxia: A phase II study. Clinical Rehabilitation, 12, 216-225.

van Heugten, C. M., Dekker, J., Deelman, B. G., van Dijik, A. J., Stehmann-Saris, F., \& Kinebanian, A. (2000). Measuring disabilities in stroke patients with apraxia: A validation study of an observational method. Neuropsychological Rehabilitation, 10(4), 401-414.

van Heugten, C. M., van Dekker, J., Deelman, B. G., Stechmann-Saris, J. C., \& Kinebanian, A. (1999). A diagnostic test for apraxia in stroke patients: Internal consistency and diagnostic value. Clinical Neuropsychology, 13, $1-11$.

Hodges, J. R., Bozeat, S., Lambon-Ralph, M. A., Patterson, K., \& Spatt, J. (2000). The role of conceptual knowledge in object use. Evidence from semantic dementia. Brain, 123, 1913-1925.

Humphreys, G. W., \& Forde, E. M. E. (1998). Disordered action schema and action disorganization syndrome. Cognitive Neuropsychology, 15, 771-811.

Iriki, A., \& Taoka, M. (2012). Triadic (ecological, neural, cognitive) niche construction: A scenario of human brain evolution extrapolating tool use and language from the control of reaching actions. Philosophical Transactions of the Royal Society $B, 367,10-23$.

Jamieson, M., \& Evans, J. J. (2015). Assistive technology for executive functions. In: O’Neill B \& Gillespie A (Eds) Assistive technology for Cognition, Hove: Psychology Press, 81-96.

Levinson, R. (1997). The Planning and Execution Assistant and Trainer (PEAT). Journal of Head Trauma Rehabilitation, 12(2), 85-91.

Liepmann, H. (1900). Das Krankheitsbild der Apraxie (motorische Asymbolie) auf Grund eines Falles von einseitiger Apraxie. Monatschrift fur Psychiatrie und Neurologie, 8, 15-44.

Luria, A. R. (1973). The Working Brain. Harmondsworth: Penguin, 398.

Manly, T., Lewis, G., Robertson, I., Watson, P., \& Datta, A. (2002). Coffee in the cornflakes: Time of day as a modulator of executive response control. Neuropsychologia, 40, 1-6.
Mayer, N. H., Reed, E., Schwartz, M. F., Montgomery, M., \& Palmer, C. (1990). Buttering a hot cup of coffee: An approach to the study of errors of action in patients with brain damage. In D.E.Tupper \& K. D. Cicerone (Eds.), The Neuropsychology of Everyday Life: Assessment and Basic Competencies Boston Dordrecht London: Kluwer Academic Publishers, 259-284.

Mihailidis, A., Boger, J. N., Craig, T., \& Hoey, J. (2008). The $\mathrm{COACH}$ prompting systems to assist older adults with dementia through handwashing: An efficacy study. BMC Geriatrics $8: 28$. Available from http://www.biomedcentral.com 14712318/8/28.

Morady, K., \& Humphreys, G. (2009). Comparing action disorganization syndrome and dual-task load on normal performance in everyday action tasks. Neurocase, 15(1), 1-12.

Morady, K., \& Humphreys, G. (2011). Multiple task demands in action disorganization syndrome. Neurocase, 17(5), 461-472.

Ochipa, C., Rothi, L. J. G., \& Heilman, K. M. (1992). Conceptual apraxia in Alzheimer's disease. Brain 115, 1061-1071.

O’Neill, B., Moran, K., \& Gillespie, A. (2010). Scaffolding rehabilitation behaviour using a voice-mediated interface for assistive technology for cognition. Neuropsychological Rehabilitation, 20(4), 509-527.

Pilgrim, E., \& Humphreys, G. W. (1991). Impairment of action to visual objects in a case of ideomotor apraxia. Cognitive Neuropsychology, 8(6), 459-473.

Pilgrim, E., \& Humphreys, G. W. (1994). Rehabilitation of a case of ideomotor apraxia. In: Riddoch, M. J., \& Humphreys, G. W. (Eds) Cognitive Neuropsychology and Cognitive Rehabilitation. Hove: Lawrence Erlbaum, 271-285.

Poek, K. (1986). The clinical examination for motor apraxia. Neuropsychologia, 24(1), 129-134.

Ponsford, J. (Ed) (2004). Cognitive and Behavioral Rehabilitation. New York: The Guilford Press, 366.

Riddoch, M. J., Humphreys, G. W., \& Price, C. J. (1989). Routes to Action: Evidence from Apraxia. Cognitive Neuropsychology, 6(5), 437-454.

Rothi, L. J. G., Ochipa, C., \& Heilman, K. M. (1997). A cognitive neuropsychological model of limb praxis and apraxia. In: Rothi, L. J. G., \& Heilman, K. M. (Eds) Apraxia. The neuropsychology of action. Hove: Psychology press, 29-49.

Rumiati, R. I., Zanini, S., Vorano, L., \& Shallice, T. (2001). A form of ideational apraxia as a selective deficit in contention scheduling. Cognitive Neuropsychology, 18(7), 617-642.

Saeki, S., \& Hachisuka, K. (2004). The association between stroke location and return to work after first stroke. Journal of Stroke and Cerebrovascular Diseases, 13(4), 160-163.

Schwartz, M. F. (1995). Re-examining the role of executive functions in routine action production. Annals of the New York Academy of Sciences, 769, 321-335.

Schwartz, M. F., \& Buxbaum, L. J. (1997). Naturalistic Action. In: Rothi, L. J. G., \& Heilman, K. M. (Eds) Apraxia: The neuropsychology of action. Hove: Psychology Press, 267-289.

Schwartz, M. F., Fitzpatrick-DeSalme E. J., \& Carew, T. G. (1995). The Multiple Object Test for ideational apraxia: Etiology and task effects on error profiles. [Abstract] Journal of the International Neuropsychological Society, 1, 149.

Schwartz, M. F., Buxbaum, L. J., Montgomery, M. W., FitzpatrickDeSalme, E., Hart, T., Ferraro, M., Lee, S. S., \& Coslett, H. B. (1999). Naturalistic action production following right hemisphere stroke. Neuropsychologia, 37, 51-66.

Schwartz, M. F., Montgomery, M. W., Buxbaum, L. J., Lee, S. S., Carew, T. G., Coslett, H. B., Ferraro, M., Fitzpatrick-DeSalme, 
E. F., Hart, T., \& Mayer, N. (1998). Naturalistic action impairment in closed head injury. Neuropsychology, 12(1), 13-28.

Schwartz, M. F., Segal, M., Veramonti, T., Ferraro, M., \& Buxbaum, L. J. (2002). The Naturalistic Action Test: A standardised assessment for everyday action impairment. Neuropsychological Rehabilitation, 12(4), 311-339.

Shallice, T., \& Burgess, P. (1996). The domain of supervisory processes and temporal organization of behaviour. Philosophical Transactions of the Royal Society of London, B 351, 14051412.

Sirigu, A., Duhamel, J. R., \& Poncet, M. (1991). The role of sensorimotor experience in object recognition. A case of multimodal agnosia. Brain, 114, 2555-2573.

Smania, N., Giradi, F., Domenicali, C., Lora, E., \& Agliotti, S. (2000). The rehabilitation of limb apraxia: A study in leftbrain-damaged patients. Archives of Physical Medicine and Rehabilitation, 81, 379-388.

Smania, N., Agliotti, S. M., Giradi, F., Tinazzi, M., Fiaschi, A., Centino, A., \& Corato, E. (2006). Rehabilitation of limb apraxia improves daily life activities in patients with stroke. Neurology, 67, 2050-2052.
Sohlberg, M. M., \& Mateer, C. (2001). Cognitive Rehabilitation. New York: The Guilford Press, 492.

Soliveri, P., Piacentini, S., \& Girotti, F. (2005). Limb apraxia in corticobasal degeneration and progressive supranuclear palsy. Neurology, 64, 448-453.

Stehmann-Saris, J. C. (2005). Occupational therapy guideline for assessment and treatment of apraxia following left hemisphere stroke. Amsterdam: Hoge-school van Amsterdam.

Vanbellingen, T. Y., Kersten, B., Van de Winckle, A., Bellion, M., Baronti, F., Muri, R., \& Bohlhalter, S. (2011). A new bedside test of gestures in stroke: The apraxia screen of TULIA (AST). Journal of Neurology, Neurosurgery and Psychiatry, 82, 389392.

West, C., Bowen, A., Hesketh, A., \& Vail, A. (2008). Interventions for motor apraxia following stroke. Cochrane Database of Systematic Reviews. 1: CD004132. DOI: 10.1002/14651858.CD004132.pub2

Wilson, B., \& Patterson, K. (1990). Rehabilitation for cognitive impairment: Does cognitive psychology apply? Applied Cognitive Psychology, 4, 247-260. 